To our knowledge no kindreds have been presented in the literature showing a case of spina bifida cystica in a family with multiple cases of spondylolisthesis. A marked association has been shown between spondylolisthesis and spina bifida occulta, since spina bifida occulta is five to 10 times more common in individuals with spondylolisthesis than in the general population (Pembrey, 1972). In the family presented by Amuso and Mankin (1967) five of the six surviving members of three generations had spondylolisthesis and spina bifida occulta.

The pattern in the family presented here is suggestive of autosomal dominant inheritance with variable expressivity. Given proper environmental conditions the genotype manifests itself phenotypically in spondylolisthesis with spina bifida occulta, the spondylolisthesis occurring during or after childhood with the spina bifida occulta developing embryonically. We suggest that the mother of the proposita carried this abnormal allele, although it was not expressed, and passed it to the proposita. Perhaps this allele, in conjunction with other aspects of the genotype and the intrauterine environment, led to the development of the multiple spinal anomalies of the proposita.

I would like to acknowledge the co-operation of The Children's Orthopedic Hospital and Medical Center in our study of the epidemiology of spina bifida cystica. Some of the data presented in this paper were obtained from consultation reports of the Division of Medical Genetics, Department of Medicine, University of Washington School of Medicine.

LOWELL E. SEVER Department of Epidemiology and International Health SC-36 and Center for Inherited Diseases University of Washington Seattle, Washington 98195, USA

REFERENCES

Amuso, S. J. and Mankin, H. J. (1967). Hereditary spondylolisthesis and spina bifida. Fournal of Bone and Foint Surgery, 49A, 507-513.

Carter, C. O. (1969). Spina bifida and anencephaly: a problem in genetic-environmental interaction. Fournal of Biosocial Science, 1, 71-83.

Lorber, J. (1965). The family history of spina bifida cystica. Pediatrics, 35, 589-595.

Newman, P. H. (1963). The etiology of spondylolisthesis. Fournal of Bone and foint Surgery, 45B, 39-59.

Pembrey, M. E. (1972). Discordant identical twins. V. Neural tube defects. The Practitioner, 209, 709-712.

Smith, D. W. (1970). Recognizable Patterns of Human Malformation: Genetic, Embryologic, and Clinical Aspects. Saunders, Philadelphia.

Wiltse, L. L. (1962). The etiology of spondylolisthesis. Fournal of Bone and foint Surgery, 44A, 539-560.

Yen, S. and MacMahon, B. (1968). Genetics of anencephaly and spina bifida? Lancet, 2, 623-626.

\section{Double Autosomal Trisomy and Mosaicism for Chromosomes No. 8 and No. 21*}

Summary. This patient was found to have a previously unreported double trisomy for chromosomes No. 8 and No. 21. She was recognized to have Down's syndrome at birth, and her subsequent development was consistent with that diagnosis. Her general health was good and there were no features suggesting an additional chromosomal abnormality. At this time there is no clearly recognized phenotype associated with trisomy 8 .

Two non-disjunctional events, occurring in meiosis and/or post-zygotic mitosis, are possible explanations of the chromosomal abnormalities found in this patient.

Double autosomal trisomy is rarely found in viable individuals, in contrast to the more frequently occurring autosomal trisomy with sex chromosomal aneuploidy. Most of the instances of double trisomy or trisomy with sex chromosomal aneuploidy have been observed in Down's syndrome. To our knowledge, double autosomal trisomy for a $\mathrm{G}$ chromosome and another autosome (either a D or an $\mathrm{E}$ chromosome) has been described in 11 liveborn children (Gagnon et al, 1961; Gustavson et al, 1962; Becker, Burke and Albert, 1963; Hsu et al, 1965; Smith, Tips, and Howard, 1965/1966; Tolksdorf, et al, 1965; Koch, Santamouris, and Ulbrich, 1967; Marks, Wiggins, and Spector, 1967; Zellweger and Abbo, 1967; Glogowska, 1969; Porter, Petersen, and Brown, 1969).

The child described here was found to have double trisomy and mosaicism for chromosomes No. 8 and No. 21, identified by Giemsa-banding patterns. The karyotype was $47, \mathrm{XX},+21 / 48, \mathrm{XX},+8$, +21 . At birth the phenotype was readily recognized as Down's syndrome, and there were no unusual features suggesting an additional chromosome abnormality. This is the first reported liveborn child with double autosomal trisomy involving chromosomes No. 8 and No. 21.

Received 24 August 1973.

* This study was supported in part by Grants No. 286 and No. 422 from the Maternal and Child Health Services, United States Public Health Service. 


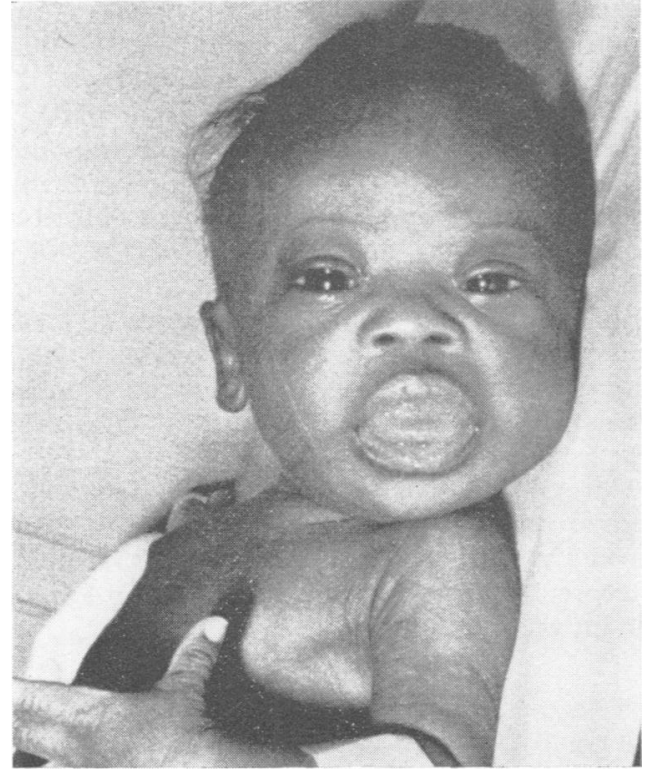

Fig. 1a. Proposita at 2 months. Typical appearance of Down's syndrome.

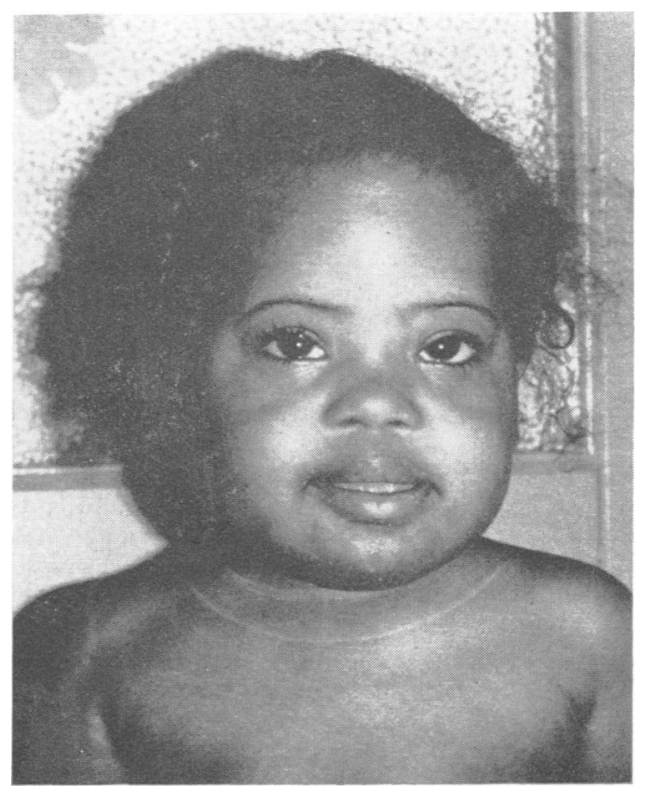

Fig. 1b. Proposita at 17 months.

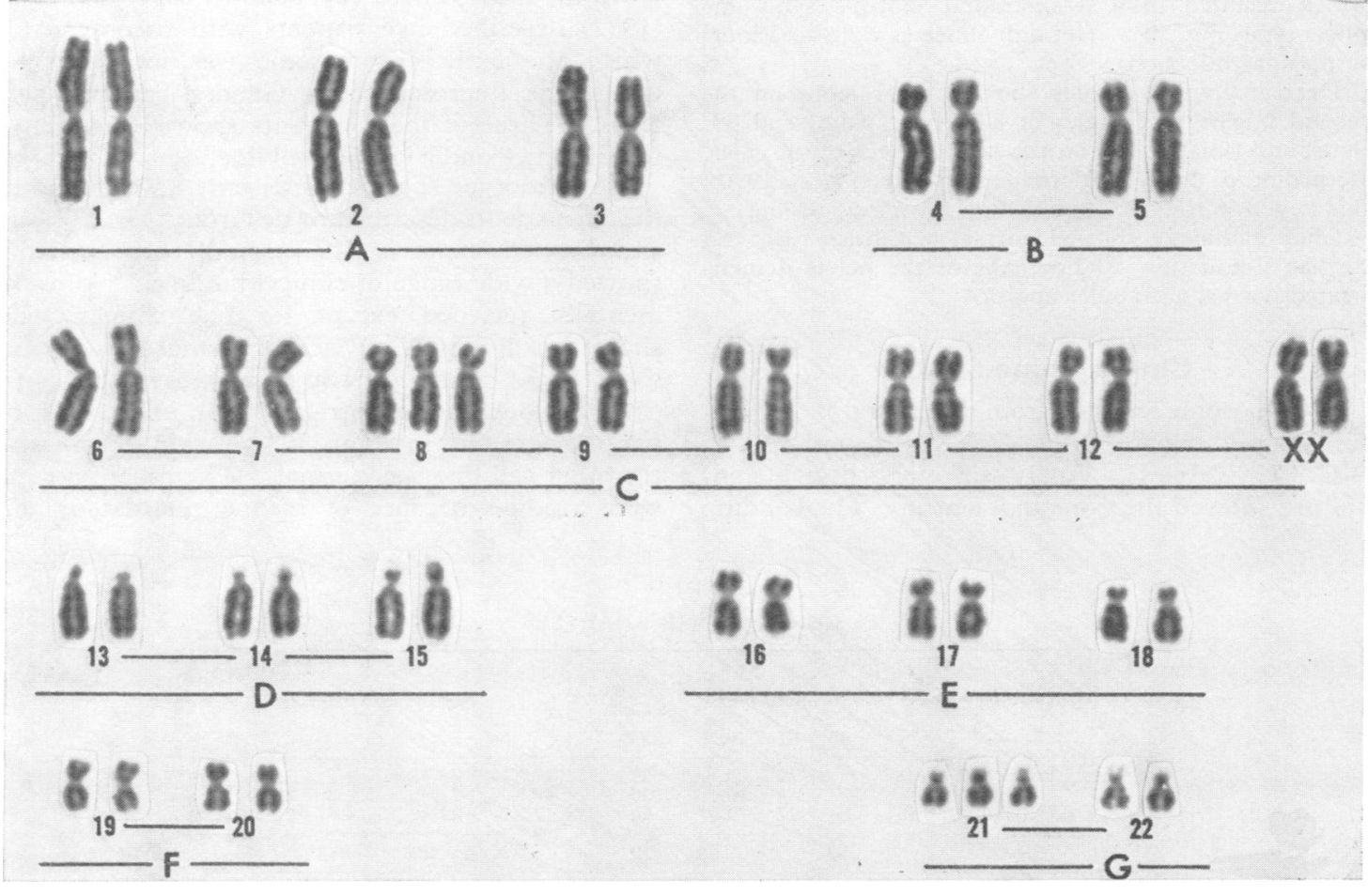

FIG. 2. Karyotype from the proposita demonstrating the cell line of $48, \mathrm{XX},+\mathrm{C},+\mathrm{G}$. (Conventional staining.) 


\section{Case Report}

Following a normal pregnancy and delivery, this female black infant (AH 181071) was born at term to an 18-year-old, gravida 2 mother and a 21 -year-old father. The parents were unrelated. Their other child was a normal 2-year-old boy. There was no family history of Down's syndrome, congenital defects, or mental retardation.

Birth weight was $2580 \mathrm{~g}$ and the child was immediately recognized to have Down's syndrome (Fig. 1a). She was hypotonic, placid, and hyperextensible at all joints. The following were present: brachycephaly, a flat facial profile, epicanthi, upward-slanting palpebral fissures, a protruding tongue, prominent lips, clinodactyly of the fifth fingers, and a deep cleft between the first and second toes. There were no cardiac murmurs and no Brushfield spots. Palmar creases were normal.

At 3 weeks of age, she was found to have a duodenal stenosis and malrotation and these were corrected by surgery. At 13 months her developmental behaviour was at the 6-month level, and at 20 months was about 9-10 months.

Growth measurements of height and weight were at about the third centile throughout the first year of life, and less than the third centile at 17 and 20 months of age. Head circumference was at about the 10th centile for age during the first 20 months of life.

As the child became older, her tongue protruded less, which resulted in a less striking Down's syndrome phenotype (Fig. 1b). Her only illnesses were occasional respiratory infections.

Dermatoglyphic studies showed ulnar loops on the second fingers, atd angles of $87^{\circ}$ (right palm) and $89^{\circ}$ (left), and tibial arches on the hallucal area of the soles. According to the Reed dermatogram (Reed et al, 1970), this is within the distribution for Down's syndrome.

Chest radiology showed normal vertebrae, ribs, and cardiac silhouette. Radiographs of the pelvis demonstrated normal acetabular angles.

\section{Chromosome Studies}

Chromosome analysis from peripheral blood culture showed two cell lines: $47, \mathrm{XX},+\mathrm{G}$, and $48, \mathrm{XX}$, $+\mathrm{C},+\mathrm{G}$ (Table I). Analysis from fibroblast (skin) culture showed the same mosaicism. The banding patterns, with the use of trypsin Giemsa-staining of Seabright (1971 and 1972) and quinacrine fluorescence staining by the method of Caspersson, Zech, and Johannson (1970) and Caspersson, Lomakka, and Zech (1971), enabled the trisomic chromosomes to be identified as No. 8 and No. 21 (Figs. 2 and 3). The predominant cell line in the blood was $47, \mathrm{XX},+21(60 \%)$ and in the skin, $48, \mathrm{XX},+8,+21$ (about $80 \%$ ).

Cells from the buccal mucosa showed $30 \%$ of 300 cells with one Barr body and no cells with two Barr bodies. Autoradiography demonstrated only one late-labelling X chromosome in the 48-cell line (four cells examined).

Chromosome analyses from the parents showed normal results. The karyotype from the mother showed a lengthened short arm of No. 15, which was interpreted as a minor variant $(15 p+)$. This variant was also found in the proposita.

\section{Discussion}

Trisomy C, often associated with mosaicism, has been reported in a number of instances; however, only recently was it possible to specify the chromosome present in the trisomic state. De Grouchy, Turleau, and Léonard (1971) and Caspersson et al (1972) described five patients with trisomy 8 , in which the extra chromosome was identified by quinacrine fluorescence or Giemsa banding patterns. Three of these patients showed mosaicism for trisomy 8 and a normal cell line.

No phenotype specific for trisomy 8 was found in the five patients described by de Grouchy et al (1971) and Caspersson et al (1972). All these patients showed a wide range of clinical findings. All were mentally retarded except for one woman who showed no abnormal physical or mental features and was studied because of two spontaneous abortions. She was found to have trisomy 8 in about $95 \%$ of lymphocytes and in about $50 \%$ of skin fibroblasts; the other cell line was normal. The other patients were studied because of mental retardation and

TABLE I

CHROMOSOME ANALYSES

\begin{tabular}{|c|c|c|c|c|c|c|}
\hline & \multirow[t]{2}{*}{ Tissue } & \multicolumn{3}{|c|}{$\begin{array}{c}\text { No. of } \\
\text { Chromosomes }\end{array}$} & \multirow[t]{2}{*}{$\begin{array}{l}\text { Total No. } \\
\text { of Cells }\end{array}$} & \multirow[t]{2}{*}{ Results of Analysis } \\
\hline & & 46 & 47 & 48 & & \\
\hline Patient & $\begin{array}{l}\text { Blood (2 mth) } \\
\text { Skin (2 mth) } \\
\text { Blood (20 mth) }\end{array}$ & & $\begin{array}{r}32 \\
4 \\
27 \\
\end{array}$ & $\begin{array}{l}23 \\
16 \\
23 \\
\end{array}$ & $\begin{array}{l}55 \\
20 \\
50\end{array}$ & $\begin{array}{l}47, \mathrm{XX},+21 / 48, \mathrm{XX},+8,+21 \\
47, \mathrm{XX},+21 / 48, \mathrm{XX},+8,+21 \\
47, \mathrm{XX},+21 / 48, \mathrm{XX},+8,+21 \\
\end{array}$ \\
\hline Mother & Blood & 10 & & & 10 & $46, \mathrm{XX}$; normal \\
\hline Father & Blood & 10 & & & 10 & 46,XY; normal \\
\hline
\end{tabular}




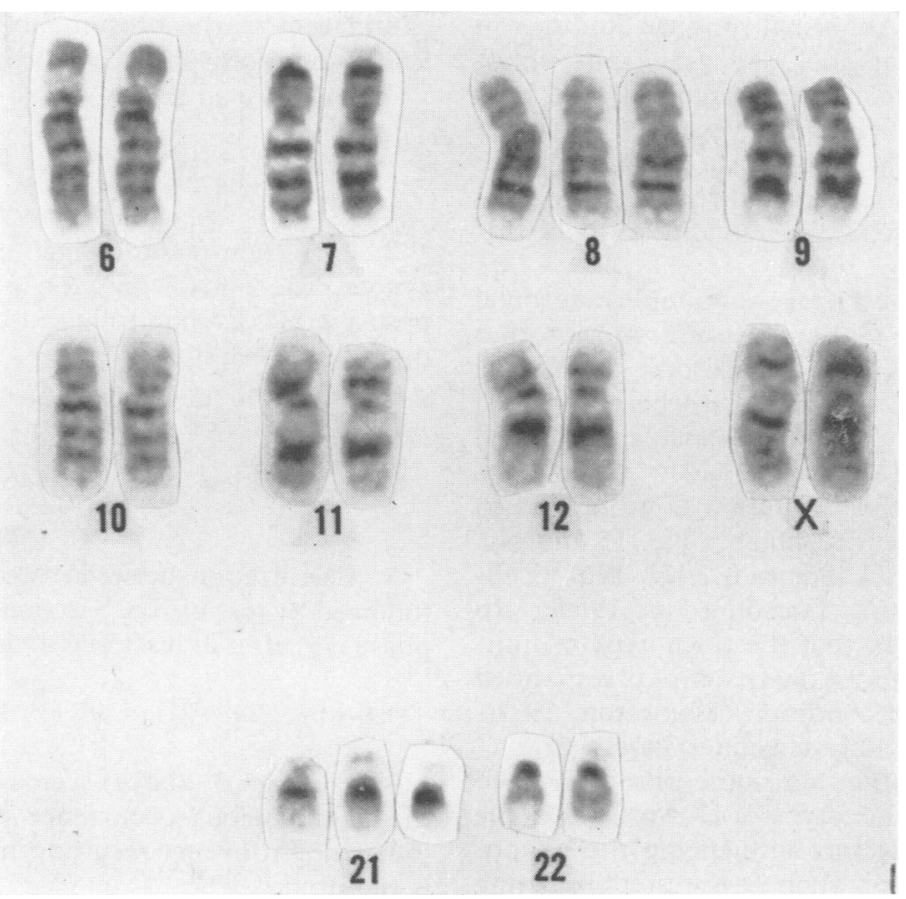

Fig. 3. Partial karyotype from the proposita demonstrating trisomy 8 and 21 in the $48, \mathrm{XX},+8,+21$ cell line. (Trypsin Giemsa-banding.)

TABLE II

DOUBLE AUTOSOMAL TRISOMY

\begin{tabular}{|c|c|c|}
\hline Double Trisomy & Karyotype & Phenotype \\
\hline $\begin{array}{l}\text { G and } D \text { chromosomes } \\
\text { Gustavson et al (1962) } \\
\text { Becker et al (1963) } \\
\text { Koch et al }(1967) \\
\text { Porter et al }(1969) \\
\text { Smith et al }(1965 / 1966)\end{array}$ & $\begin{array}{l}48, X X,+D,+G(\text { or } 48, X X,+D,+Y) \\
48, X Y,+D,+G \\
48, X Y,+D,+G \\
47, X Y,+D / 47, X Y,+G / 48, X Y,+D,+G \\
47, X X,+G / 48, X X,+D,+G\end{array}$ & $\begin{array}{l}\text { Patau's syndrome } \\
\text { Down's syndrome (primarily) } \\
\text { Not Down's syndrome } \\
\text { Down's syndrome (primarily) } \\
\text { Down's syndrome (atypical) }\end{array}$ \\
\hline $\begin{array}{l}\text { and } E \text { chromosomes } \\
\text { Gagnon et al (1961) } \\
\text { Hsu et al (1965) } \\
\text { Tolksdorf et al (1965) } \\
\text { Marks et al (1967) } \\
\text { Zellweger and Abbo (1967) }\end{array}$ & \multirow{2}{*}{$\begin{array}{l}\text { 48,XY, + E, + G } \\
46, X X / 48, X X,+E,+G \\
47, X Y,+G / 48, X Y,+E,+G \\
47, X Y,+G / 47, X Y,+E \\
46, X Y / 47, X Y,+E / 47, X Y, \\
+ \text { G } / 48, X Y,+E,+G \\
47, X Y,+G / 48, X Y,+G,+E\end{array}$} & $\begin{array}{l}\text { Edwards' syndrome (primarily) } \\
\text { Edwards' syndrome } \\
\text { Edwards' syndrome } \\
\text { Down's syndrome } \\
\text { Down's syndrome (primarily) }\end{array}$ \\
\hline Glogowska (1969) & & Down's syndrome \\
\hline $\begin{array}{l}G \text { and } C \text { chromosomes } \\
\text { Present case }\end{array}$ & $47, \mathrm{XX},+21 / 48, \mathrm{XX},+8,+21$ & Down's syndrome \\
\hline $\begin{array}{l}\text { G chromosomes and } \\
\text { unidentified autosome } \\
\text { Dekaban (1965) }\end{array}$ & $48, \mathrm{XX},+\mathrm{G},+\operatorname{mar}$ & Down's syndrome \\
\hline $\begin{array}{l}\text { D and E chromosomes } \\
\text { Schmidt et al (1967) } \\
\text { Zellweger and Abbo (1967) } \\
\text { Garson et al (1969) }\end{array}$ & $\begin{array}{l}46, X X / 48, X X,+D,+E \\
47, X Y,+D / 47, X Y,+E \\
47, X X,+D / 47, X X,+E / 48, X X,+D,+E\end{array}$ & $\begin{array}{l}\text { Edwards' syndrome } \\
\text { Patau's and Edwards' syndromes } \\
\text { Edwards' syndrome (primarily) }\end{array}$ \\
\hline
\end{tabular}


congenital defects. Abnormal physicál findings in several of these patients included strabismus, clinodactyly, vertebral and rib abnormalities, and possible abnormalities of the great vessels. Published photographs of several patients showed a long face with large, prominent ears, small chin and protruding lower lip. Growth did not appear to be adversely affected.

We were able to find 11 cases of double autosomal trisomy involving a $G$ chromosome and another autosome, either a D or E chromosome (Table II). One case of Down's syndrome has been reported with $48, \mathrm{XX},+21$ and an additional, unidentified small chromosome (Dekaban, 1965). Three additional cases of double trisomy for a D-group and an E-group chromosome (presumably No. 13 and No. 18) have been reported (Schmidt et al, 1967; Zellweger and Abbo, 1967; Garson et al, 1969). In general, it was thought that the phenotype of individuals with double autosomal trisomy corresponded with the more severe condition (Hamerton, 1971). About half of the double trisomies involving a G chromosome and another autosome were associated with the less severe phenotype of Down's syndrome (Table II). Other factors influencing the phenotype may be significant, such as the predominating cell line, particularly in critical periods of fetal life, and the actual distribution of cell lines throughout the body. Clinical familiarity with Down's syndrome may generally bias towards its recognition, rather than that of the more severely affected phenotypes associated with trisomy 13 or 18 .

Of double trisomic individuals with trisomy $G$, the other autosome was a D chromosome in about half of the cases and an $\mathrm{E}$ chromosome in the other half. Mosaicism occurred in all but one of the five cases of double trisomy $\mathrm{G}$ and $\mathrm{E}$, and in only one of the five instances of double trisomy $G$ and $D$. In general, mosaicism is more frequent in the single aneuploidy of trisomy $\mathrm{E}$ than in trisomy $\mathrm{D}$.

Trisomy for No. 8 chromosome was only recently recognized. Some years ago, it was thought that three autosomal trisomies were all that would be found in man, and that very likely an additional autosome of the size of the $C$ group would be incompatible with life. At present, it appears that trisomy 8 is clearly compatible with life and may be associated with few congenital defects. To date, mental retardation is a constant feature of the nonmosaic individuals with trisomy 8 .

There are a number of mechanisms that would explain the double trisomy-mosaicism of $47,+21$ and $48,+8,+21$ found in our patient:

1. Post-zygotic non-disjunction occurring after the first division in a trisomic zygote, followed by elimination of the presumably non-viable cell line lacking one autosome.

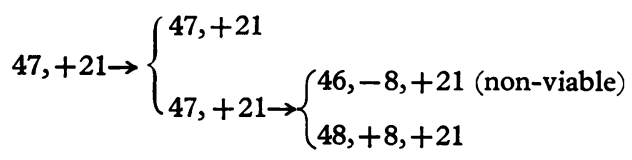

2. Two non-disjunctional events in a euploid zygote, one non-disjunction occurring at the first post-zygotic division followed by elimination of the monosomic cell lines.

$$
46 \rightarrow\left\{\begin{array}{l}
45,-21 \text { (non-viable) } \\
47,+21 \rightarrow\left\{\begin{array}{l}
47,+21 \\
47,+21 \rightarrow\left\{\begin{array}{l}
46,-8,+21 \text { (non-viable) } \\
48,+8,+21
\end{array}\right.
\end{array}\right.
\end{array}\right.
$$

3. Fertilization between two aneuploid gametes, followed by loss of No. 8 in one cell line (eg, by anaphase lag) after at least one division.

$$
(24,+8)+(24,+21)=48,+8,+21 \rightarrow\left\{\begin{array}{l}
47,+21 \\
48,+8,+21
\end{array}\right.
$$

Mechanism 3 (above) seems the least likely since the simultaneous occurrence of two unusual and independent events resulting in aneuploid gametes is required.

We are grateful for the technical assistance of $\mathrm{Dr}$ Joseph A. Towner and Mr Paul Brager.

Miriam G. Wilson, Atsuko Fujimoto, and OMAR S. AlFi

From the Genetics Division, Department of Pediatrics of the University of Southern California School of Medicine, Los Angeles CountyUniversity of Southern California Medical Center and Children's Hospital of Los Angeles, California, USA

REFERENCES

Becker, K. L., Burke, E. C., and Albert, A. (1963). Double autosomal trisomy (D trisomy plus mongolism). Proceedings of the Staff Meetings of the Mayo Clinic, 38, 242-248.

Caspersson, T., Lindsten, J., Zech, L., Buckton, K. E., and Price, W. H. (1972). Four patients with trisomy 8 identified by the fluorescence and Giemsa banding techniques, fournal of Medical Genetics, 9, 1-7.

Caspersson, T., Lomakka, G., and Zech, L. (1971). The 24 fluorescence patterns of the human metaphase chromosomesdistinguishing characteristics and variability. Hereditas, Genetiskt Arkiv, 67, 89-102.

Caspersson, T., Zech, L., and Johansson, C. (1970). Analysis of the human metaphase chromosome set by aid of DNA-binding fluorescent agents. Experimental Cell Research, 62, 490-492.

De Grouchy, J., Turleau, C., and Léonard, C. (1971). Etude en fluorescence d'une trisomie C mosaique, probablement 8: 46,XY/ 47,XY, ?8 + . Annales de Génétique, 14, 69-72.

Dekaban, A. (1965). Twins, probably monozygotic: one mongoloid with 48 chromosomes, the other normal. Cytogenetics, 4, 227-239. 
Gagnon, J., Katyk-Longtin, N., de Groot, J. A., and Barbeau, A. (1961). Double trisomie autosomique à 48 chromosomes $(21+$ 18). Union Médicale du Canada, 90, 1220-1226.

Garson, O. M., Baikie, A. G., Ferguson, J., and Greer, C. H. (1969). Double autosomal trisomy and mosaicism for three cell lines in man. Fournal of Medical Genetics, 6, 209-215.

Glogowska, I. (1969). Mosaicism 47/48 in a patient with Down's syndrome. Neurologia i Neurochirurgia Polska, 19, 263-266.

Gustavson, K.-H., Ivemark, B. I., Zetterqvist, P., and Böök, J. A. (1962). Post-mortem diagnosis of a new double-trisomy associated with cardiovascular and other anomalies. Acta Paediatrica, 51, 686-697.

Hamerton, J. L. (1971). Autosomal abnormalities-Group G. In Human Cytogenetics, vol. 2, chap. 5, pp. 253-257. Academic Press, New York and London.

Hsu, L. Y. F., Schwager, A. J., Nemhauser, I., and Sobel, E. H. (1965). A case of double autosomal trisomy with mosaicism: $48 / \mathrm{XX}$ (trisomy $18+21$ ) and $46 / \mathrm{XX}$. Fournal of Pediatrics, 66, 1055-1060.

Koch, F., Santamouris, C., and Ulbrich, F. (1967). D + G Trisomie bei einem Patienten mit Rothmund-Syndrom. Zeitschrift für Kinderheilkunde, 99, 1-13.

Marks, J. F., Wiggins, K. M., and Spector, B. J. (1967). Trisomy 21-trisomy 18 mosaicism in a boy with clinical Down's syndrome. Fournal of Pediatrics, 71, 126-128.
Porter, I. H. Petersen, W., and Brown, C. D. (1969). Double autosomal trisomy (trisomy D + G) with mosaicism. Fournal of Medical Genetics, 6, 347-348.

Reed, T. E., Borgaonkar, D. S., Conneally, P. M., Yu, P. L., Nance, W. E., and Christian, J. C. (1970). Dermatoglyphic nomogram for the diagnosis of Down's syndrome. Fournal of Pediatrics, 77, 1024-1032.

Schmidt, G. W., Stibane, H., Ulbrich, F., and Griesse, H. (1967) Edwards-syndrome with double trisomy D and $\mathrm{E}$ (mosaicism). (Edwards-Syndrom mit Doppeltrisomie D and E [mosaik]. Klinische Wochenschrift, 45, 634-638.

Seabright, M. (1971). A rapid banding technique for human chromosomes. Lancet, 2, 971-972.

Seabright, M. (1972). The use of proteolytic enzymes for the mapping of structural rearrangements in the chromosomes of man. Chromosoma, 36, 204-210.

Smith, G. S., Tips, R. L., and Howard, H. (1965/1966). Autosomal mosaicism occurring in conjunction with Down's syndrome. American fournal of Mental Deficiency, 70, 218-222.

Tolksdorf, M., Lehmann, W., Hansen, H. G., and Wiedemann, H. R. (1965). Edwards-syndrom mit aussergewöhnlichem chromosomalem Befund. Zeitschrift für Kinderheilkunde, 93, 55-63.

Zellweger, H. and Abbo, G. (1967). Double trisomy and double trisomic mosaicism. American fournal of Diseases of Children, 113 329-337.

\section{Turner Phenotype : Mosaic 45,X/47,XY, $+18 *$}

Summary. A 14-year-old girl with Turner phenotype is described, whose lymphocyte and skin fibroblast cultures both revealed a $45, \mathrm{X} / 47, \mathrm{XY},+18$ chromosomal mosaicism. In blood cultures one third and in fibroblasts $7 \%$ of the cells had 47 chromosomes. The identity of the $\mathrm{Y}$ and the supernumerary 18 were determined by fluorescence and Giemsa banding patterns. The patient is of normal intelligence and does not exhibit any signs of masculinization or stigmata of trisomy 18 .

There are several instances of mosaicism with $\mathrm{X}$-monosomic and 21-trisomic cell lines. Cohen and Davidson (1972) published one case of a mosaic 45,X/47,XX, +21 , and Prieur et al (1972) one of $45, \mathrm{X} / 47, \mathrm{XY},+21$. Several cases of mosaic $45, \mathrm{X} / 46, \mathrm{XX} / 47, \mathrm{XX},+21$ (Pfeiffer, 1968) and one

Received 28 August 1973.

* Reprint requests to: Professor W. Schmid, Abteilung für Medizinische Genetik; Kinderspital Zürich, Steinwiesstrasse 75, CH-8032 Zurich, Switzerland. case of mosaic 45,X/46,XY/47,XY, +21 (Edgren, de la Chapelle, and Kääriäinen, 1966) have been reported. To our knowledge the present case is the first one involving an extra autosome 18.

\section{Case Report}

The proposita is the third daughter of healthy unrelated parents; the father was 38 years and the mother 41 years at her birth. All the family is of short stature, the father being $162 \mathrm{~cm}$, the mother $152 \mathrm{~cm}$, the 21-yearold sister $150 \mathrm{~cm}$, and the 18 -year-old sister $160 \mathrm{~cm}$. The patient was born by Caesarean section at 36 weeks; birth weight was $2400 \mathrm{~g}$. Swelling of the dorsum of both feet was noted at birth and persisted for more than one year. The patient was said to have been always smaller than her sisters at comparable ages, but otherwise her physical and mental development was normal

At 12 years of age she was referred to this hospital because of short stature (length $117.7 \mathrm{~cm}$, weight $25.2 \mathrm{~kg}$, both below third centile) and absence of pubertal signs. She presented the following stigmata of Turner's syndrome: multiple pigmented naevi, prominent auricles, short broad neck with slight pterygium, broad chest with widely spaced hypoplastic nipples, relatively large clitoris, hyperextensibility of elbow joints, and short fourth fingers. Radiology of both hands revealed short fourth metacarpals, a coarse trabecular pattern of the bone, and a bone age of 9-10 years, giving a predicted adult height of only $139 \mathrm{~cm}$.

Sex chromatin was studied in buccal smears and in hair root preparations (Schmid, 1967a and b). The chromosomes from blood cultures were studied in 